\title{
Robot Pets as "Serious Toys"- Activating Social and Emotional Experiences of Elderly People
}

\author{
Pirita Ihamäki ${ }^{1}$ (D) Katriina Heljakka ${ }^{2}$ \\ Accepted: 12 July 2021 \\ (C) The Author(s), under exclusive licence to Springer Science+Business Media, LLC, part of Springer Nature 2021
}

\begin{abstract}
When robots are used as part of meaningful play, for example to enhance wellbeing, they can be considered "serious toys". Our study examines the potential of robotic pet toys viewed as companions, which activate social and emotional experiences of the elderly by increasing their wellbeing. In order to study the benefits of using Golden Pup, a commercial robot dog, we designed and performed a research intervention at a senior day activity center with 10 participants of ages $65-80+$ years who were joined by a playful group of preschoolers. In this study, we were mainly interested in the firsthand user experiences.This study suggests how robotic pets can be used to activate the social and emotional experiences of elderly, and illustrated the role of building a relationship with a robotic pet. We present novel results on how a robot dog with a natural interface (NUI) may be used to evoke social and emotional experiences in older adults as part of playful, intergenerational group activities.
\end{abstract}

Keywords Social robot $\cdot$ Commercial robot pets $\cdot$ Elderly experiences $\cdot$ Emotional experience

\section{Introduction}

Over the next decade, robotic pets (social robots representing animal forms) will become not only more natural and capable of action, but also more available for use (Aylett 2002, Yokoyama et al. 2004). New York became the first state in the United States to test robotic pets with isolated elderly because of coronavirus. The results showed that using pets to lower social isolation is highly successful for about $70 \%$ of pilot participants reporting a decrease in isolation after one year (Smith 2020). The shapes of the animal robots are classified into three categories: 1) familiar animals (e.g. dog, cat), 2) nonfamiliar animals (e.g seal), and 3) imaginary animals or characters. (Shibata and Wada 2011). Some robots are explicitly meant to represent simulate (non-human) animals, for example pet robots or toy robots. Coeckelbergh (2011) presents how long-term relationships may develop between human and non-human like relationships with robots that may develop

Pirita Ihamäki

pirita.ihamaki@prizz.fi

Katriina Heljakka

katriina.heljakka@utu.fi

1 Prizztech Ltd, Pori, Finland

2 University of Turku, Pori, Finland between children and their toy robot or between adults or elderly and pet robots. Previous research on robot animals demonstrate their role in education and healthcare. (Sharkey and Sharkey 2011) Huggable Bear, PooChi, Pleo and like in this article, the Golden Pup robot dog aim to enrich the daily life of human by acting as playful companions.

Recently, pet like robots have been introduced to produce for social and emotional benefits associated with the interaction and emotional bond between human and companion animals, such as entertainment, relief, support and enjoyment. (Heerink et al. 2012) In our understanding, simple robotic pets function generally as entertaining entities, which provide playful enjoyment. Nevertheless, depending on their context of use, and in particular, their users, these companion animals have the potential to function as deliverers of more than temporary fun. In fact, we believe that robot pets could assist in increasing human wellbeing, by using them as 'conversation starters' and play partners that invite embodied and multimodal interaction, even play between generations. In our study, our focus is not to look at robot pets as therapy tools for dementia care. Instead, we want to research social and emotional experiences of the elderly, by using the robotic pet. We also want to understand the capacity of a (commercial) robot toy to give comfort and activity for the elderly. This study extends previous research (Ihamäki and Heljakka, Bates, 2020, Heljakka and Ihamäki 2019, Schulman-Marcus et al. 2019, Marsilio et al. 2018) on the Golden Pup robot toy. In 
the study, we observed how a group of elderly people aged between 65 and 85 years react to and interact with the robot dog. In the study, our goal was to understand better how robotic pets like commercial, smart toys of the present can be used to enhance wellbeing, by activating elderly at a day activity centre.

Many researchers in the field of Human-Robot Interaction have used the term attachment to describe human's emotional responses to various types of robots. (Huang et al. 2020) Previous studies suggest that contact with robot dogs can positively affect the wellbeing of elderly people, but there is a lack of research investigating the cause of these effects with other aspects of the firm operations (Broekens et al. 2009) Paro, the robot seal, is the most well researched example increasing health and social care demand (Moyle et al. 2013). P r e v i o u s studies suggest numerous benefits of interaction with Paro, particularly for elderly people with dementia (Jøranson et al. 2015, Wada et al., 2005, Saito et al. 2003, Liang et al., 2017, Petersen et al. 2017, Robinson et al. 2015) However, there is limited availability of studies of 'real-world' companion robots, in which the focus is on wellbeing outside of the medical context. Bradwell et al. (2020) present the results of a longitudinal diary study, in which a six-month study investigated the real-world implementation of the Paro robot with elderly people. They also used the Joy for All Golden Pup and Cat for this study (Bradwell et al. 2020). In our previous work with the Golden Pup robot dog, we have investigated the responses of elderly and preschoolers by considering the robot dog in terms of ludic literacy (Heljakka and Ihamäki 2019). The paper at hand, however, deepens the analysis of the elderly peoples' reactions and responses, and explores the capacities of the robot dog as an activating tool. A later study and independent work completed in 2021, investigated how the Golden Pup could assist in preschoolers' learning of social-emotional skills during a short research intervention. This study was conducted with a new group of participants only consisting of preschoolers.

In this study, our aim is to address the gap in current research by focusing on how an entity such as a robot dog may trigger positive experiences in elderly and in this way, contribute positively on their wellbeing. We are interested in emotional and social experiences with the commercial robot dog, which activates the elderly to dicuss earlier experiences with pets and to share the emotional experience that the robot dog gives them during an integrational group activity. We deliver new findings on human-robot interaction with a focus on social and emotional experiences of elderly people as part of casual and a focus on social and emotional intergenerational group acitivities. We propose that robotic pets could be used as part of structured playful intergenerational group activities to enhance the wellbeing of older adults.

\section{Related Work}

Robot toys are the most likely application of commercial-level social robots in the near future (Nácher-Soler et al. 2015). Previous examples include the Sony AIBO robotic dog and Ugobe's Pleo, which are designed in line with the thought of functioning as artificial pets. Although the border between actual robots and contemporary, anthropomorphized toy robots seems to be blurring, one way to distinguish these two groups of "relational artefacts" (Turkle et al. 2006b) is their accessibility for the users. Tangible technologies allow the interaction and manipulation of digital information that is communicated through physical objects like toys (Shibata and Tanie 2001).

Toy designers have understood that the natural interfaces (NUI) are the most appropriate for the interaction of players because they allow them to interact with a computer application through natural capabilities, such as voice commands and allowing, for example, the robot toys to move. The Golden Pup employed in our study, represents interactive technology of this kind and has similarities with the seal robot Paro. For example, the Golden Pup has sensors that respond to touch and sounds (see Fig. 1.).

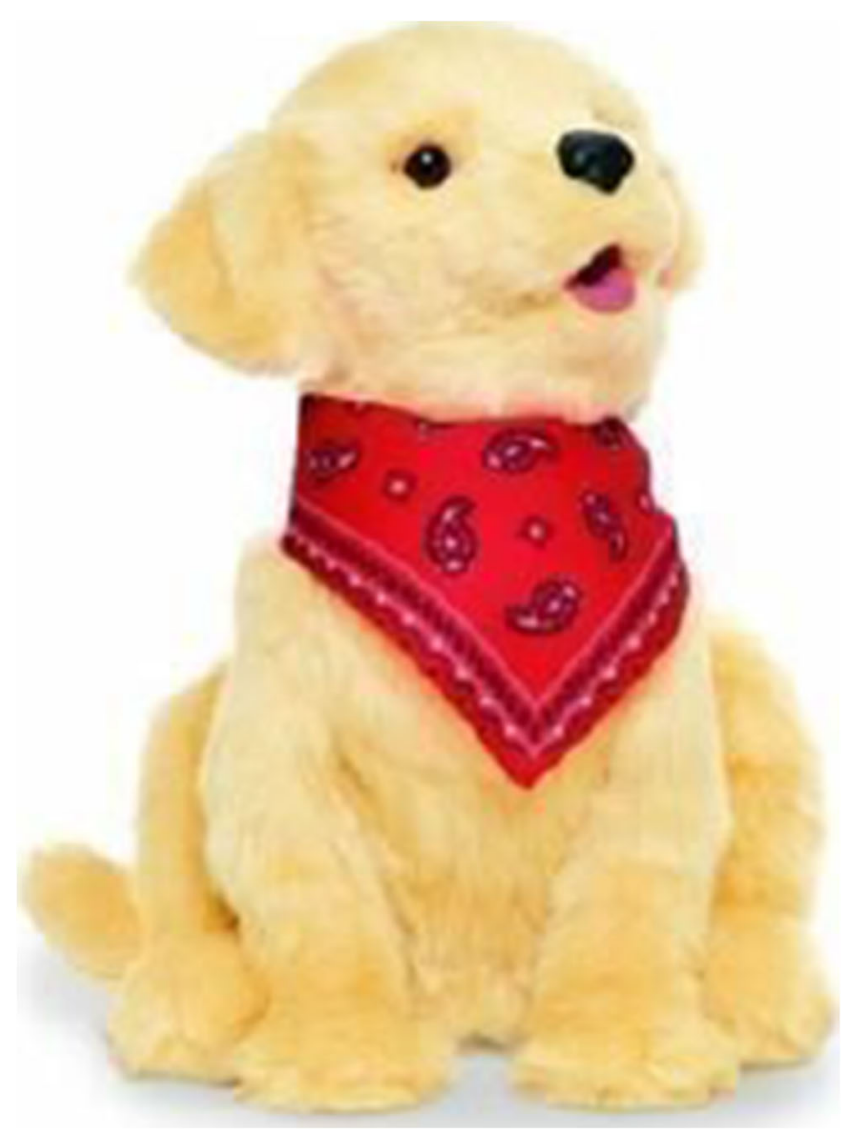

Fig. 1 Golden Pup robot dog by Joy for All, used in our study 


\subsection{Human-Robot Relationships with Robotic Pets}

De Carolis et al. (2017) suggest that a social robot should not just provide task-oriented support, but it should establish a social relation with user. In their research, the researchers employed the NAO robot in the context of Ambient Assisted Living (AAL). In their conclusions, the researchers state that besides assisting an elderly in various tasks, the robot needs to establish a social long-term relation with him to enforce his trust and confidence. According to Kahn et al. (2004a, b), robotic pets are described to "inform on our understanding of the human-robotic relationship". A similar description is given by Friedman et al. (2003). Robotic pets can provide companionship to older adults (Shibata 2011), as suggested, for example, in a study with the iCat (Heerink et al. 2006). In particular, pets like dogs are known to form strong social bond with their owner that manifests itself in potective behaviors or playful and excited attitudes, depending on their internal state and social cues exchanged between the animal and its owner (Fong et al. 2003). To leverage similar benefits of human-animal interaction, the field of robot dogs draws from metaphors that highlight the similarities between the robot and known animals in order to communicate affordances and facilitate a more effective, personal, and emotional interaction (Norouzi et al. 2019) in various applications, such as companionship (Paro 2019, Sony AIBO 2019) and therapy (Moyle et al. 2015).

Social roles of robots such as robot nannies, robot caretakers of elderly people, robot teachers for children, offering comfort and companionship that promote the development of responsibility and interaction, will be more personalized and intimate (Sharkey et al. 2020). Currently, some companion robots, such as the seal robot Paro awarded 'the most therapeutic robot in the world' (Shibata 2011) demonstrate that the area of affective computing is interested to produce utilitarian, yet toy-like, therapeutic aids for the elderly (Jones and Deeming 2008).

Our present study builds on the idea of seeing the possibility of elderly people to become activated by the robot pet in terms of emotional responses, which are believed to lead to emotional attachment. According to Norman (2004), emotional attachment can be seen as the sum of cumulated motional episodes of users' experiences with a device in various context areas. These user experience episodes can be categorized into three dimensions, which occur when a user uses a product or sees it for the first time. Therefore, in interaction with a robotic pet, the dimensions of the user experience can be categorized as follows:

- Attribution of labeling emotions level: This is the first impression of a product (robotic pet) through its appearance, as users spontaneously judge easily the products when they are first tried and used. Moreover, this describes what kind of first impression a user gets and what kind of emotion the product delivers during the first time. We consider that in research interventions using a robotic pet, the participants are likely to encounter this type of artificial entity for the first time in their life.

- Behavioral level: At this level participants use and experience a product (here, robotic pet). They appraise its functions, find out how well the functions fulfill their needs, and how easy it is to use the product. (Weiss et al. 2009) We speculate, that in the case of robot pets, the firsthand encounter is guided by the non-utilitarian elements of surprise and delight of experiencing the tangible interface, movement and sound of the robot pet, instead of the utilitarian perspective on its use, such as asking 'what can this robot pet do for me?'

- Reflective level: At this level consciousness takes part in the process. The user understands and interprets things and remembers past experiences of similar instances. In earlier studies with robot pets, study participants have reported to have reminisced the actions of their own live pets and other memorable animal experiences. (Weiss et al. 2009)

In this paper, we present a study of a robot dog intervention to receive a better understanding of the firsthand social and emotional experiences of interaction with a robot pet, which relate to Norman's three dimensions of experience presented above. Research on robot pets shows that interactions with animal-like robots can have positive effects similar to those form of interaction with real animals (Bernabei et al. 2013, Robinson et al. 2015, Sefidgar et al. 2016). One of the most used form of interactions is touch, especially when interacting with real animals. (Robinson et al. 2015, Sefidgar et al. 2016). Touch can have different meanings depending on the context, for example, the intent of a touch could be affectionate, comforting as supportive, or even playful (Jones and Yarbrough 1985, Yohanan and MacLean 2012). In addition, another study showed that the social message that was communicated to a robot pet varied based on the user's emotional state, which also affected the response that was expected from the robot (Jung et al. 2017). Based on these findings it is therefore likely that recognizing and acting on these different meanings will benefit interaction with animal-like robots.

Furthermore, the development of robot pets with more advanced social capabilities such as touch and speech recognitions might result in more intelligent interaction facilitating emotional and social interaction, which could help to better adapt to the needs of the elderly and could for example in playful sharing make the interaction more interesting for a broader audience.

\subsection{Robotic Pets for Older Adults}

Melson et al. 2009 write," Robotic pets may ultimately have a place within the complex relationships that humans have with 
animals" (Melson et al. 2009). Reeves and Nass (1996) have shown that people behave socially towards artifacts like computers, but it can be assumed that socially designed robot pets even intensify these effects. For example, the emotional interaction with robotic pets has been investigated in therapeutic contexts. Real pets cannot be present in certain settings such as hospitals and they provide meaningful social interactions (Miklósi and Gácsi 2012). Banks et al. (2008) found that AIBO could be as effective as a real dog in reducing loneliness in elderly patients living in a long-term care facility. A number of studies with the robotic dog AIBO have already been conducted. (Kahn et al., 2004a, b, Friedman et al. 2003). However, several studies have presented how Paro, a robotic seal, has been used in nursing homes by focusing on the introduction and acceptance of this companion robot. This robotic animal assistant is to provide emotion recognition and response (affective computing solutions) in a way that robots can respond to elderly and children's emotions with empathy and compassion. Robotic pets involve humans in personal experiences and simulate behaviors that require care and attention.

Furthermore, there are indications that stroking and interacting with Paro could lower blood pressure in elderly people which is similar to the effects found for interaction with real animals (Eachus 2001, Robinson et al. 2015) Marti et al. (2005) conducted a study on the therapeutic qualities of the seal robot Paro; their results showed a clear role of the robot in mediating social exchange and stimulating attachment and engagement. Moreover, there is research that has provided some evidence of benefits of using robotics with the elderly, particularly as a result of interacting with robot pets (Tamura et al. 2004, Banks et al. 2008, Kanamori et al. 2002). The results of these studies indicated that interaction with the robot could improve mood, make people more active, lower stress, and promote social contact with the robot pet as well as with peers and nursing staff (Wada et al. 2004, Wada and Shibata 2007).

\subsection{Touch Interaction with Animal-Like Robot Pet Companions}

Since AIBO is a hard-shelled animal-like robot (Fujita 2001), compared with Paro soft fur-covered robot, there is the elephant-like robot Probo and Golden Pup dog pet which are more pleasant to touch and can evoke affective behaviors such as stroking and hugging (Wada and Shibata 2007, Saldien et al. 2010, Shibata and Wada 2008, Robinson et al. 2015, Ihamäki and Heljakka 2021). Although most pets such as Paro (Wada and Shibata 2007), AIBO (Fujita 2001), Probo (Saldien et al. 2010) Hasbro Joy for All Golden Pup (Ihamäki and Heljakka 2021) and JustoCat are equipped with touch sensors, for a more natural interaction animal-like robots should be able to automatically understand and respond to different types of touch and interpret those touches within context. There are several studies, which discuss social touch for robots.
The studies have been conducted on the recognition of touch gestures (e.g. stroke, pat, and tickle), emotions (e.g. happiness, fear, and sadness), and social messages (e.g. greeting, attentiongetting, and showing affection) from pressure sensor data (Knight et al. 2009, Silvera-Tawil et al., 2014).

For this reason, designers have started to develop robot pets that focus specifically on touch interaction. For example, the Huggable robotic teddy bear has its own full-body somatosensory system to sense and process human touch (Stiehl et al. 2005, Knight et al. 2009). Another example is the Haptic Creature that is a zoomorphic lap pet that can sense human touch all over its body and stiffening of the ears (Yohanan and MacLean 2012, Altun and MacLean 2015, Sefidgar et al. 2016). The use on simulated breathing for animallike robots has been explored further in the CuddleBit robots (Cang et al. 2015, Bucci et al. 2017).

These small zoomorphic robots react to human touch by expressing emotions through different breathing patterns resulting in haptic affective display. In our research we have realized that touch is one of key interaction elements especially for elderly people, when using a robot pet as a playful tool to activate social and emotional experiences. The current study builds upon previous research on the effectiveness of existing animal-like robot dog Golden Pup in active elderly social and emotional experiences and tries to engage elderly day activity center by multimodal interaction including touch. We investigate the effectiveness of Golden Pup in social activities, where elderly can share earlier animal experiences and could benefit from interaction with an animal-like robot.

\subsection{Play as Social Activity with Robotic Pets}

Since it's not unusual for people to treat systems and devices as social beings (Kanamori et al. 2002), it seems likely that people treat embodied agents as such. This means that the extent to which they do so seems to be related to a factor that is often related to as either 'presence', or more specifically 'social presence'. In theirs study, Johanson et al. (2019) found out how the use of self-disclosure and forward lean by a health care robot can increase human engagement and attention behaviors. Many research projects that are related to humanrobot user experience incorporate the concepts of embodied interaction. (Batliner et al. 2004, Lee and Nass 2003, Heerink et al. 2007). According to Fong et al. (2003) and Breazeal (2003), social robots share a number of features that reliably elicit perceptions of animacy and causality in children and elderly: they are personified, embodied, adaptive and autonomous. Consequently, social robots can learn how to communicate, use natural cues, respond to emotions in humans, selforganize, and pull on people in psychological rather than artifactual ways. (Fong 2003, Breazeal 2003, Kahn et al., 2004a, b). However, social influences of robots that are collocated (i.e in the same space) with humans, questions rise up how 
humans perceive and think about their robotic pet companions, critically involving characteristics related to the robot pet itself (Powers and Kiesler 2006). Furthermore, robot pets have been used as communication tools but playfulness is also assumed to be an important factor concerning acceptance and use of robot pets (Leite et al. 2008, Looije et al. 2008).

\section{Method and Data}

\subsection{Focus Gorup with Play-Test}

We conducted focus group interviews including 18 participants (elderly people, 62-85 years of age and preschool children, who were 5-7 years old). The 9 elderly people had owned pets at some point in their life and only one of the elderly participants had never owned a pet.

The goal of the focus group interviews combined with a play-test was to explore older adults' interaction with a robot pet. We aimed to understand the participants social and emotional experiences, their perceptions of robotic pets, and the ways they expressed interest or disinterest in interacting with the robot in a focus group interview combined with a play-test session. At the beginning, the researchers informed the participants about their earlier work with robotic toys, and asked them for informed consent to participate in the study. The robot dog under scrutiny, Golden Pup, is an interactive robot toy and that looks and acts like a live dog. It is important to note that this robot dog is designed for all ages, that is a commercial toy, which is both accessible and relatively affordable, for example on the Amazon website.

We were interested in the capacity of the robot dog to function as a tool supporting social interaction a social and an emotional tool, which may activate the elderly but also could invite them to play together with preschoolers as assistants (the participating children guided and invited the elderly to play-test the robot dog). The focus group interview began with a researcher first asking the children to share the stories of their soft toys' stories (a child had brought their soft toy into the focus group interview), and demonstrate, how they play with them. The researcher then asked the elderly to share memorable experiences of pets or other animals. This conversation started the interaction between the elderly and the children as they were not familiar with each other. Participants were told that robotic pet used to provoke feedback and discuss how seeing them affected their perceptions. During focus groups, we intentionally went back and forth between real pets' experiences by asking to tell memorable experiences with real pets and animals and at the same time to look at how they used the robot dog as an interaction tool (e.g. asking benefits of one over the other). (Lazar et al., 2016) This was done also to engage participants in a way that would get them thinking of the questions they had about the robotic pet as well as obtain initial impressions they interacted with other participants. Next, participants were asked questions such as what they thought of the idea of having a robotic pet in their arms, whether they would want to interact with one, and how they would want to interact with it, and if they are ready to play with the robot dog together with the children. The robot dog was passed around the participants, who were informed about the features of the robot dog and encouraged to test these features (e.g., responds to touch). Additionally, the goal of introducing the robot dog was to stimulate conversation and provide participants with concrete examples that varied along dimensions of interaction type and appearance.

During the focus group interview and play test, we intentionally asked the participants about their earlier and memorable experiences with real pets and other animals and at the same time, observed how they used the robot as an interaction tool (Lazar et al. 2016). This is to say that children have functioned as assistant of the study, but the findings of the study focus on the elderlys' interaction with the robot dog. However, we acknowledge how the presence of the children may have influenced the interaction of the elderly with the robot dog, especially in terms of their playing with the robot dog under the eyes of the elderly. Nevertheless, we consider the reactions of the elderly to represent their genuine and highly personal responses to the robot dog. What guided our interest in particular was our curiosity about Golden Pup's persuasion strategies in terms of its capacity to promote social and emotional responses. Another criterion for the robot pet was that it represents a multi-dimensional experience with a tangible, natural interface (NUI). In order to explore the capacity of the Golden Pup to function as a facilitator of social and emotional experiences in elderly people, the main focus of this case study was to gather responses of elderly interacting volutarily with the Golden Pup in a free exploration mode. Our main goal was to assess the interaction on the behavioral and reflective level together with preschool children who frequently visit the day activity center.

\subsection{Participants}

This study is part of the intergenerational play research (Heljakka and Ihamäki 2019) interested in interaction and experiences of seniors and preschoolers. The study was conducted in June 2019 with $(n=10)$ elderly people (ages 6580 years, 3 male, 7 female) at a day activity center in Finland. At times, the preschoolers and seniors do different kind of activities together. The organized group activity (the robot dog intervention), which also included a interview situation was documented in the focus group of the center. The participation in the robot dog intervention was introduced as an optional activity. The authors, who functioned as the two researchers, were joined by one assistant responsible for the video-recording, and one day activity center staff member, 
two kindergarten teachers, and 8 preschool children. One researcher acted as the supervisor, who gave the instructions and made questions, while the other was observing and taking notes. This case study presents the results of this onetime session, consisting of $80 \mathrm{~min}$ of interaction in total.

\subsection{Robot Dog Golden Pup}

We identified a low cost interactive robotic pet (by Hasbro) called "Joy for All Companion Pets" made commercially available in 2016. The pet-like robot Golden Pup from the sence was selected for the play intervention including a focus group interview at an elderly day activity center.

The battery-operated Golden Pup representing an accessible and affordable robotic dog, is suitable for multigenerational playful interaction (it is recommended for ages 5-105 years) and it is envisioned to create novel and meaningful play situations employing sound, haptic movements and realistic visualization. The recommended age category is based on the Golden Pup Companion Pet's marketing materials. We want to draw attention to this new approach of targeting lowcost robotic pets: Generally toys are designed with children in mind, but the Golden Pup robot toy is marketed as an "all age-group toy". It is envisioned to transcend the traditional ways of thinking about toys as a" life-long toy", or play partner enjoyed by a broad range of users. The Golden Pup has sensors that respond to touch and sounds. "You can feel the heartbeat while touching it and it can respond back to your voice commands", the description of the Golden Pup says (Kanamori et al. 2002). The robotic pet Golden Pup responds to petting and hugging with motion sensors. With movements and sounds the robot simulates a real animal, especially through playful barks and head turning. The play patterns of the chosen robot dog present according to the toy marketer mobile play: The Golden Pup reacts to touch "with puppy-like movements and sounds", haptic/object play: The Golden Pup features a realistic coat"; and auditive play: the Golden Pup comes with a "simulated heartbeat, and authentic sounds and responds with 'Bark Back' technology". Despite its complex hidden technology, the Golden Pup is a nonconnected toy. (Joy for All Companion Pets, 2021, Ihamäki and Heljakka 2020) Previously, the Golden Pup has been tested in several studies (Joy for All Companion Pets, 2021, Ihamäki and Heljakka 2020, Schulman-Marcus et al. 2019). These studies focused on the effect of Golden Pup or Cat robot toy in long-term interaction of children, but also the elderly. Although results of earlier studies show how the Golden Pup robot toy could activate the elderly to receive social and emotional experiences, this study demonstrates novel results on how to activate elderly in a day activity center by facilitated interaction with the Golden Pup assisted by preschoolers.

\subsection{Design and Procedure}

During the group activity and interview situation, the authors first raised questions about the participants own pets and other memorable animal experiences in their lives. The 8 of the 10 participants had owned pets earlier in their lives. The elderly each shared their experiences with their domestic animals, such as pet cats and dogs. This conversation was carried out during some $20 \mathrm{~min}$. After the introductory discussion, we first introduced the robot dog to the participating preschoolers, who then introduced the robot dog for the elderly.

All preschoolers were invited to a free play session as the authors observed the spontaneous and unconstrained interaction with the Golden Pup. The experience was intended to provide the participants with an open-ended play experience, thus enhancing verbal communication with the Golden Pup. After this they introduced the robot toy Golden Pup for the elderly. At this stage, all participants had the possibility to familiarize themselves with the robot $\operatorname{dog}$ and to discuss the Golden Pup's actions (see Figures 2 and 3). The duration of this part was about 30 minutes. When the play time was over, the researcher instructed all participants to answer some questions about the session. For example, each elderly was asked the same questions, such as: "How do you feel about this robot dog?", and "What kind of emotions does this robot dog raise in you"?

One of the researchers, two preschool teachers and one elderly day activity center staff member guided the interaction, while the other researcher observed and took notes of any relevant contextual information. The duration of the group activity and interview with the preschool- children and elderly was some 30 minutes. The whole experimental intervention session was some 80 minutes in length. The complete session was video- recorded for analyses.

\subsubsection{Social Presence with the Golden Pup}

We used two different types of questions in the group activity and interview to establish the sense of presence. The questions were divided in three parts and designed to investigate the reflective level of emotional attachment. First, we used questions interested in social presence and emotional experiences related to their experiences with animals. The second set of questions was concerned with social presence, social experience and empathy. The third part of the questions based on the interaction with the robot dog, during which we observed the elderly's behavior and interaction linked to social presence (Batliner et al. 2004). The questions consisted of 10 questions addressing emotional attachment, social activity and emphatic interaction modalities with the robotic dog. (see Table 1 and Table 2). 


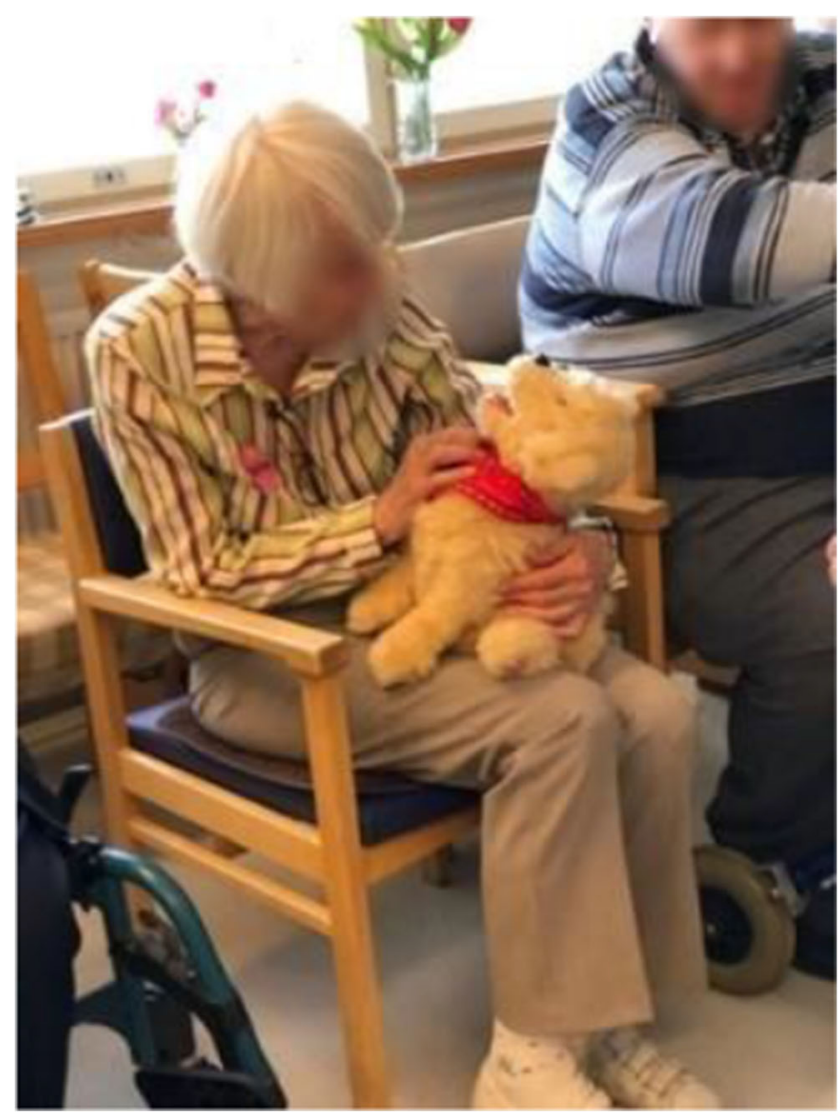

Fig. 2 The elderly experience interaction with the Golden Pup for the first time

\subsubsection{Emotional Responses with the Golden Pup}

A second set of questions featured the attribution of labeling emotions (with one word). This methodology is used in different types of research to establish a subject perception of an artifact (Schulman-Marcus et al. 2019, Forlizzi et al. 2003). We created a list of 10 words of emotions, which could be used to describe the interaction between the elderly and the robot toy. Half of these words referred to a social entity and social experiences with the robot dog: joy, sadness, surprise, uncaring, emphatic, antipathy, soft, rough, active, neutral. We

\section{Table 1 Example of Social Presence Questions}

1. What kind of feelings does the Golden Pup give you when you take it in your arms for the first time? What kind of emotions does this raise in you?

2. How does the Golden Pup respond to you? How does that make you feel?

3. What kind of social activities can the Golden Pup offer for you?

4. Which kind of interaction with the Golden Pup do you estimate as "natural'? Which kind of interaction did you like the most?

5. Which kind of interaction and emotions could you image for the Golden Pup in the future?

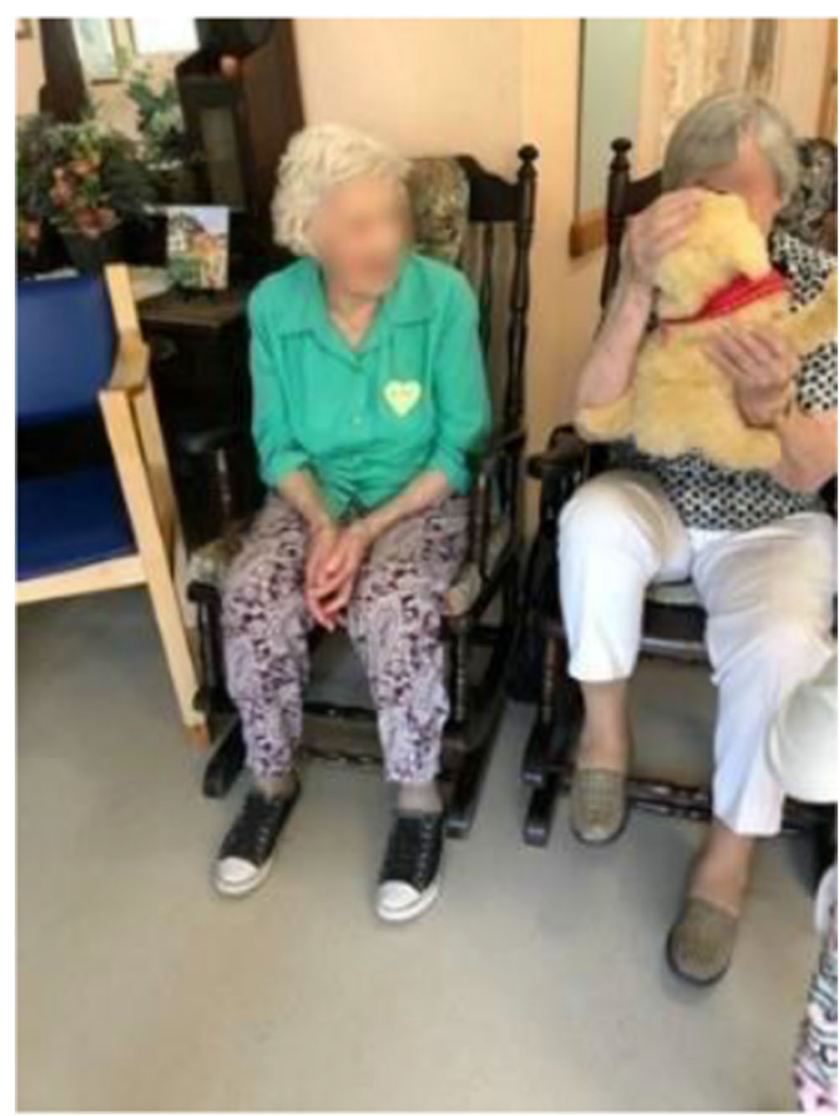

Fig. 3 The elderly experience interaction with the Golden Pup for the first time

chose seven of these labeling emotions, which arose from the data. Labels are: joy, surprise, emphatic, soft, active, touch and neutral, classified for six labels from the data. 'Joy' belongs to the 'big' emotions, while the other ones belong to 'emotion-relation/emotion-prone uses states. 'Surprise' means in this study that elderly experienced surprises when touching and speaking to the Golden Pup. In this study, we understand that emotional responses arise when the elderly start to reminiscence her/his own pets and treat the robot dog as a real animal (through sensitive touch). In this study 'soft' means a situation, when the elderly starts hugging and touching the robot dog and 'petting' it as real animal. 'Active' means that the robot dog activates the elderly to react and respond by

Table 2 Questions in third method features

1. Is it easy to communicate and interact with the Golden Pup?

2. Do you think that the Golden Pup can activate you in your daily life?

3. Do you think that the Golden Pup will listen to you and understand you?

4. Could the Golden Pup be your play fellow/robot dog?

5. Would you feel better, if the Golden Pup is with you when you are at home alone? 
talking to the robot dog, at the same time reminiscing stories of their real pets in earlier phases of their lives. 'Neutral' in this study, means a situation when the elderly do not react very much to the robot dog and don't care for the robot toy by, for example, 'petting' it. (Forlizzi et al. 2003).

\subsection{Emotional Attachment with the Golden Pup}

The third method featured a set of questions that could simply be answered with 'yes' or 'no'. These questions addressed specifically the emotional attachments with the Golden Pup after the interaction.

\subsection{Participatory Observation}

To evaluate the behavioral level of Norman's emotional attachment concept, one of the researchers conducted unstructured participatory observation. Notes were taken on interesting and unexpected behavior as well as the setting in general. The observations were also documented by video-recording.

\subsection{Data Analysis}

The focus group interaction was video-recorded, transcribed, and verified by a member of the research team. Data analysis was conducted through a grounded theory approach (Chang et al. 2013). We coded the data with two themes independently to generate codes and grounded them into higher level themes and second material was coded based on verbal action of participants, because we wanted to understand social and emotional actions between participatns and with the robot dog. We selected codes with high level themes and merged to create a codememo. The rest of transcripts were coded with this codememo, which was updated to reflect emerging themes. The research team then related the codes to each other through an iterative process of memoing and theorizing, engaging in constant comparison of data to understand and refine a set of high-level themes. This approach requires reflecting on our position as researchers and the perspective we bring to the analysis. We keep in mind previous research that challenges the ways that the elderly is currently perceived in robotics (Lazar et al. 2016, Frennert and Östlund 2014, Neven 2010, Šabanovic 2010) and are receptive to alternative viewpoints and reactions to these stereotypes that are voiced by the elderly.

\section{Results}

The main goal of this free exploration study was to validate if a setting of an intergenerational group activity situation can help to understand elderly's first-time responses to a robotic pet with a focus on activating the social and emotional experiences of elderly people. To conduct our study with elderly participants, we invited them to a research intervention: a voluntary intergenerational activity with preschool-aged children at a day activity center. None of the participants had previously interacted with the robot dog under scrunity, the Golden Pup. Here is an example (a conversation) of robot dog-elderly-preschooler interaction.

Preschooler: "We have two dogs, one of which is really old."

Elderly: "Just like me [old], but is it nice to play with someone old too."

Preschooler: Yes, and this "Golden Pup" is also wonderful [puts the robot dog in the arms of an elderly person].

Elderly: [He takes the "Golden Pup" robot dog in his arms and strokes it. He also hugs it.]

Robot Dog: Raises the gaze towards the elderly and yawns. Preschooler: The child smiles and says that when the robot dog is stroked, it moves its eyes.

Elderly: "Oh, it listens to us."

Robot Dog: Turns its head in the direction the sound is coming from.

Preschooler: "Isn't that wonderful?"

Also, how their peers 'keep' their pets, raised some concerns. For example, one elderly person literally said that: "A dog is not a toy for the elderly". Another claimed: "Dogs do not belong to apartment buildings". Nevertheless, the reminiscing around dogs and cats as a part of their former lives prompted positive and emphatic responses in the elderly. Many said that they wished to own a pet, if it only was possible for them. This robot dog intervention carried out as an intergenerational group activity situation worked as a rewarding experience for the elderly people, because all participants were happy to join the activity and after the intervention, asked to have more activities of this kind. Results of the present study demonstrate that elderly people were enthusiastic about the Golden Pup, they engaged actively with the robot dog, even played with it (made physical contact and talked to it) anthropomorphizing the Golden Pup as if it was a real pet. The summarized emotions caused by immediate and automatic reactions by the elderly had in common an enthusiasm for the Golden Pup when first introduced. This enthusiasm could be observed through statements like "Oh, it looks like real dog", "Where I can buy this kind of dog, because I can't keep a real one anymore" and "May I touch him/her", as well as actions like hugging and talking with the Golden Pup as if it was a real dog. Interestingly, the positive experiences observed at the emotional level lasted even though the elderly experienced the robot dog together with the preschool children. However, when the elderly started to talk to the Golden Pup 
telling about their experiences with their own pets or other animals, the robot dog recognized the voice and moved its head as if it was listening to the elderly's story. The elderly described that the Golden Pup understands them and responded very personally when the robot dog moved its head to the direction where their voice was coming from.

\subsection{The Behavioral Level - Emotions through the Action}

The robot dog intervention described in this paper stimulated the elderly participants reminiscing of earlier experiences of pets and other animals through interaction with the robot dog, and raised different emotions when they interacted with the robot dog (see Figs. 2-3). Therefore, shapes, feelings of touch, autonomous behavior, and responses are the features that are required to be present in the robot dog. (Shibata and Wada 2011) The results of our study indicate that interaction with the Golden Pup increased elderly people's social interaction. The following behavioral patterns could be observed:

- Joy: This behavioral pattern is defined by emotion-relation/emotion-prone use state, when the elderly enjoyed taking care and playing with the robot dog. It was very clear to see, how the elderly enjoyed holding the robot dog in their arms and at the same time, discussed their memorable animal experiences. For example, one elderly (male) told the following story about meeting an elk in the forest: When the elderly was a child, he went to the forest and an elk started to follow him. The elderly told that he started to be afraid and climbed on a big stone and stayed there a while, but the elk was still following him. The elderly thought that if he goes home then elk will not follow him anymore. After he arrives in the home yard, the elk is still following him. The elderly had a rifle in his arm and he shot into the sky to frighten the elk. The elk ran away and at the same time, the elderly understood that the elk was young and his/her mother had rejected it to learn to live alone. The elderly felt sad. This moment was also very intimate because the Golden Pup was looking straight in the eye and blinked when the elderly person spoke to it. It felt that was listening to the elderly's story.

- Surprise: The pattern of surprise is characterized by observing the elderly's reaction of surprised emotion when touching and speaking with the Golden Pup. The elderly wanted to actively interact with the Golden Pup by touching its fur. Usually, the first reaction when the Golden Pup was looking in their eyes and looking like it listens to them and at the same time blinks its eyes, which makes an elderly become surprised. Also, when they hug the Golden Pup they can feel its heartbeat, which makes the robot dog seem alive.
- Empathy: The behavior pattern is defined by showing emotional feelings for the robot dog and interacting and simulating action as interacting with a real animal. For example, the behavior of one elderly addressed the positive emotions to figure out what the robot dog wants him/ her to do, as the dog's eyes are blinking all the time. "It looks like it is listening to me". The emotional experiences seem to raise with the elderly, when they interact and start to remember their own animal experiences. For example, one elderly (male) said that he has once taught two parrots to speak Finnish language during his vacation in Mexico. He really liked the parrots and left the parrots behind when returning to Finland. When the elderly shared his empathic experiences socially by telling of his previous animal experiences, he was at the same time hugging the robot dog.

- Softness: This pattern describes the experiencing of the softness of the robot dog's natural interface. The Golden Pup demonstrates that it could be a companion for elderly people, especially those who are allergic to real dogs. The elderly expressed this experience, for example by saying: "This dog is so cute and soft", and "Where I can buy my own Golden Pup, because I can't have a real dog anymore?"

- Active: This behavioral pattern is defined by actively communicating and playing with the Golden Pup robot dog. When the elderly received the robot dog in their arms by the preschool children they became more active and socially present. The Golden Pup robot dog can express emotion when the elderly touch it. For example, stroking the dog activates positive emotional experiences and reduces stress. Some elderly described that this feels like stroking a real animal, at the same time holding the Golden Pup in their arms. One female participant tells us that she always has had a cat in her house. When she was a child, she fell in love with cats and if some dogs tried to chase her cat, she would run them off. She felt that when she owns a cat she needs to defend and take care of them. For her, cats have always given comfort and happiness. Earlier research has found that "nurturing" robot pets is a consequence of increased levels of oxytocin, which appears to reduce stress. (Sharkey and Sharkey 2012) To give an example, when Wada and Shibata (2006) videotaped interactions between a Paro robot seal and a group of elderly care home residents, they found evidence that the social interactions between the residents themselves increased, at the same time that physiological indicators showed reduced stress levels (Wada and Shibata 2006). This means that robot pets can increase social interaction and activities especially at elderly daycare centers.

- Touch: The robotic pet like in here the Golden Pup offered several interactive features. Sensors in two locations 
of the head and cheeks of the pet responded to user touch and activated a reciprocal "nuzzling" effect. The Golden Pup responds to human touch by e.g. yawning. Touchactivated sensors were located in the upper abdomen and back of the pet. A light sensor located in the pet's head detected when light entered room and the pet vocalized in response to the light stimuli, depending upon chosen settings. The robot dog barked depending on the settings. (Hudson et al., 2011) The study shows that when elderly touch the robot dog, they hug and relax, and it looks like it is easy for them to talk about their earlier animal experiences. Even if one of the elderly was afraid of dogs, she was not afraid of the robot dog. She even claimed to like the robot dog Golden Pup.

- Neutral: This behavioral pattern is defined by that elderly don't care or not actively play or nurture the robot dog (meaning they are less interactive with it). One of the elderly (a female) says that she did not like animals in her childhood. But even so, she had a story to tell: She describes that some boys were taking kittens that could not be found a home for in the forest, but the kittens always found their way back home.

This story is to illustrate, that with robot pets, which look like a real animals and simulate human behavior generally associated with interaction with animals, we should remember that not everybody likes animals or they may even be afraid of them. In this way, it is possible to see that not all robot pets that look like a real animals do not cause the same positively pleasurable feelings. The results of the study described in the paper at hand support the viewpoint presented by Turkle et al. (2006a) according to which elderly people were prepared to interact with robots: "Seniors felt social 'permission' with the robots presented as a highly valued and 'grown up' activity." Based on these findings, it seems like the elderly see that the Golden Pup robot dog could provide companionship for them. Moreover, it appears that, if used at elderly day activity centers, robot dogs of this kind could activate social and emotional experiences and give companionship, which could potentially add extra interest to an elderly person's life and might even improve their social wellbeing.

\subsection{Summary of the Intervention}

The purpose of the study was to investigate the firsthand responses of elderly people during a robot dog intervention organized at an elderly day activity center together with a group of preschoolers. In this article, we aimed to discuss how robotic pets can be used to activate the social and empathy experiences of elderly, and the role of reciprocity inbuilding a relationship with a robotic pet. To explore the impact of a robot dog when used in a group activity situation, we set out to investigate the capacity of a commercial toy robot and "companion animal", to function in causing increasing (and immediate) wellbeing. Our research employed the Golden Pup, a robot pet or companion animal, which represents a tangible interface, more exactly, NUI, or a robot with a natural (soft, fur-like) interface. The robot dog, belonging to the series of Joy for All Companion Pets has received more than 1,300 Amazon shopper left five-star review comments (Garrity 2019). In our research, we position this robot dog as a "Serious Toy", meaning that the toy has a purpose outside of leisurely play. Our study focused on Norman's categorization of user experiences: Attribution of labeling emotions, Behavioral level, and Reflective level of experience. To find out about these dimensions of experiences as part of an intergenerational group activity, we asked the participants of our study, the 10 elderly people, questions related to social presence, emotional responses and emotional attachment with the robot dog under scrutiny. More specifically, we focused on the behavioral level of experience meaning interaction with the Golden Pup. For example, in a recent study comparing and contracting the preferences of robot pets and older adult participants, elderly expressed a preference for interactive features (such as life-simulation and personalization) that were not perceived by robot dog Golden Pup as having the same importance (Bradwell et al. 2019). In our study, we could even see that one of the participants was afraid of dogs, but claimed to like the Golden Pup. In this way, we speculate how this kind of robot dog could help those who fear real dogs, and could potentially, function as a primary therapy tool for those with animals fears.

We present novel results on how a robot dog with a natural interface may evoke social and emotional experiences as part of playful group activities. Our study shows that a robot dog intervention with the Golden Pup triggered emotional responses in elderly people. In the paper, we described the first hand responses to the Golden Pup as experiences that were joy, surprise, empathic, soft, active, touch or neutral. To sum up, the results show that the key dimensions of Golden Pup was its welcoming appearance, its aesthetics, soundscape and gentle movement, which all contribute to the robot pets playability (Fig. 4).

\section{Discussion}

Based on our research, it is possible to see how robot pets like the Golden Pup can facilitate experiences of companionship and also make elderly more active in terms of reminiscing animal experiences in their earlier lives or being socially present in the 'here and now'. The results of the study show that individuals are expected to physically interact, even play with the robot dog by touching and hugging the robot dog Golden Pup. This playful interaction is also guided by imaginative responses to the robot dog, anthropomorphized like a real 


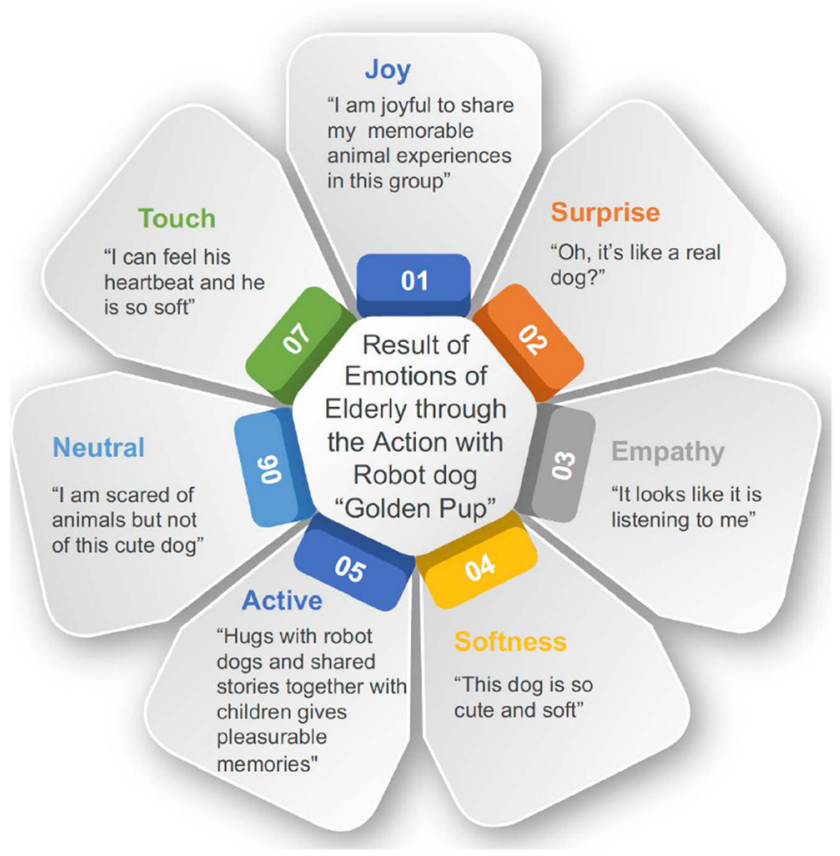

Fig. 4 Emotions of elderly through the interaction with the robot dog "Golden Pup"

pet by all of the participants in our study. The results of our study show that the mood of the elderly people improved even during this short intervention time - the elderly relaxed and had a good time together with the robot dog.

The results show high engagement when elderly have experienced physical touch, communicating with the pet. The elderly also used the robot pet as a communication tool with others, including storytelling, which they shared in the focus group interview. The results of our observation show that interaction with the Golden Pup robot dog made the elderly people laugh and become more active, for example, more talkative in sharing their histories with domestic and other animals. Their facial expression changed, softened, and brightened. The social interaction increased: The Golden Pup robot dog encouraged participants to communicate with each other as well the experiences with their own pets became a common topic of conversation, which they extended by telling about their other animal experiences in the group.

Thus, the general atmosphere became more reciprocal and energetic as the elderly shared socially some common feelings about the robot dog and as they shared experiences of empathy together. According to Keys (2002) emotional wellbeing is the presence of positive and the absence of negative emotions. The interviews indicate that interaction with the Golden Pup could induce a positive affective state such as playfulness and could activate participants to speak about general animal experiences. In addition, the results show that the Golden Pup robot toy could stimulate communication between participants in the elderly day activity center as well as between health-care providers and especially in this study, with interacting with the robot dog - enjoying its welcoming children. As positive relations with others contribute to psychological wellbeing (Keys 2002), Golden Pup is perceived to improve wellbeing in this area as well. Both findings are in agreement with the results form literature reviews on the effects of social robots and especially pet robots in care for the elderly. We also want to bring into discussion how to use commercialized robots to activate responses in a playful way in daily life of elderly (Bemelmans et al., 2012, Kachouie et al. 2014). Although the described research intervention was set up as an intergenerational group activity, it is apparent that a robot dog like the Golden Pup may even function as part of solitary interaction, meaning time alone with the robot dog. For example, thanks to its sensor technology, the Golden Pup reacts to movement and sound and may react by inviting its human partner to "play" with it, no matter of the player's age. We believe that these interactive affordances can encourage active participation in interaction, cause positive emotions, reduce feelings of loneliness and improve overall quality of life. The novelty aspect of the study at hand is to introduce the robot dog as an active tool with whom the elderly can share emotional and social experiences with the intergenerational group, consisting of both children and elderly. Finally, it is in place to bring up the matter of the age of the players and the evolution of the audiences of "serious toys" like robotic companion animals of the present: According to its age recommendation, the Golden Pup is aimed for players aged 5105 years. Although this broad target group communicates a playful marketing message, it encourages us to consider the suitability of commercial robot pets as intelligent 'toyfriends' for a much broader audience than what is considered typical for 'smart' toys, mainly targeted to young children. Potentially, this idea also mirrors the relatively long human relationships with live dogs and other domestic animals and brings up the question: If real dogs are to be considered lifelong partners, can robot dogs be considered as life-long robotic companions?

\section{Conclusions and Future Work}

"Pets play an important companion role whatever your age" (Jeffrey-Wilensky 2019). In our study, we have focused on playful interaction of elderly people with a companion technology robot dog. The findings suggest how even momentary interaction with the Golden Pup, a commercial robot dog, not only evokes empathic responses towards the robot dog itself, but thanks to its multimodal affordances, natural interface and socially presented play session as part of a group activity, may activate the elderly to reminiscence past experiences of relationships with animals while being in the present by appearance, sound, gentle movement and soft interface. In the future, we envision robotic pets to receive more realistic features, for 
example, in their capacity to move. The elderly people, who joined our study were interested in increasing the interactivity of the robot pet and suggested new functions, such as enabling the pet to learn skills and tricks.

To conclude, we believe that consumer robotics such as companion technologies like robot pets can be used in elderly day activity centers to activate the emotions of the elderly, and to give them pleasurable playful and social experiences, simultaneously through activating memories of the past and enjoying the present. In this way they can be perceived as "serious toys", meaning playthings with a purpose.

However, we believe that consumer robotics should offer more natural interfaces and affective interaction rather than technology convergence. In this way robotic dog can act more like real dogs and offer experiences of empathy, compassion and companionship to their human friends of any age. Indeed, Yohanan and MacLean (2012) showed that positively natured touch can be used to convey different intentions to an animal-like robot, that is: protective, comforting, restful, affectionate, and playful. Taking these various intentions into account could avoid mistakes such as a robot reacting negatively to a playful, yet slightly rough, touch interaction (e.g tossing). We think if Golden Pup was able to better understand the intention behind an interaction the robot toy could adapt its response to the participants needs (Jung et al. 2017). These kinds of robot pets as companion robots can be used to enhance the wellbeing of elder adults and they are suitable for healthy older people who still live in their own home. However, more research into their needs and playful preferences will be necessary. Matching the needs of a target group is important to increase the change that users will accept the technology, especially robot technology as part of their daily activities (Broadbent et al. 2009).

\section{References}

Altun, K., \& MacLean, K. E. (2015). Recognizing affect in human touch of a robot. Pattern Recognition Letters, 66, 31-40. https://doi.org/ 10.1016/j.patrec.2014.10.016.

Aylett, R. (2002). Robots: Bringing intelligent machines to life? Barron.

Banks, M. R., Willoughby, L. M., \& Banks, W. A. (2008). Animalassisted therapy and loneliness in nursing homes: Use of robotic versus living dogs. Journal of the American Medical Directors Association, 9(3), 173-177. https://doi.org/10.1016/j.jamda.2007. 11.007 .

Bates, M. (2019). Robotic pets: A Senior's best friend? IEEE Pulse, 10(4), 17-20. https://doi.org/10.1109/MPULS.2019.2922565

Batliner, A., Hacker, C., Steidl, S., Nöth, E., D’Arcy, S., Russell, M., and Wong, M. (2004). "You stupid tin box" - children interacting with the AIBO robot: A cross-linguistic emotional speech corpus. In Proc. LREC 2004, Lisbon, Portugal.

Bemelmans, R., Gelderblom, G. J., Jonker, P., \& de Witte, L. (2012). Socially assistive robots in elderly care: A systematic review into effects and effectiveness. Journal of the American Medical Directors Association, 13, 114-120. https://doi.org/10.1016/j. jamda.2010.10.002.

Bernabei, V., De Ronchi, D., La Farla, T., Moretti, F., Tonelli, L., \& Ferrari, B. (2013). Animal-Assisted Interventions for elderly patients affected by dementia or psychiatric disorders: A review. Journal of Psychiatric Research, 47, 726-773. https://doi.org/10. 1016/j.jpsychires.2012.12.014

Bradwell, H., Winnington, R., Thill S., Jones, R. B. (2020). Longitudinal Diary Data: Six Moths Real-World Implementation of Affordable Companion Robots for Older People in Supported Living. In: HRI 20' Companion, March 203-206, 2020, Cambridge, United Kingdom. doi:101145/3371382.3378256.

Bradwell, H. L., Edwards, K. J., Winnington, R., Thill, S., \& Jones, R. B. (2019). Companion robots for older people: The importance of usercentred design demonstrated through observations and focus groups comparing preferences of older people and roboticists in south West England. BMJ Open, 9(9), e032468. http://dx.doi.org/10.1136/ bmjopen-2019-032468

Breazeal, C. (2003). Toward sociable robots. Robotics Autonomous Systems, 42(3), 167-175. https://doi.org/10.1016/S0921-8890(02) 00373-1

Broadbent, E., Stafford, R., \& MacDonald, B. (2009). Acceptance of healthcare robots for the older population: Review and future directions. International Journal of Social Robotics, 1, 319-330. https:// doi.org/10.1007/s12369-009-0030-6.

Broekens, J., Heerink, M., \& Rosenthal, H. (2009). Assitive social robots in elderly care: A review. Gerontechnology, 8(2), 94-103. https:// doi.org/10.4017/gt.2009.08.02.002.00.

Bucci, P., Cang, X. L., Valair, A., Marino, D., Tseng, L., Jung, M.M., Rantala, J., Schneider, O.S., Maclean, E. (2017). Sketching cuddlebits: coupled prototyping of body and behaviour for an affective robot pet, In: Proceedings of the SIGCHI Conference on Human Factors in Computing Systems (CHI) (Denver, CO), 36813692. https://doi.org/10.1145/3025453.3025774

Cang, X. L., Bucci, P., and MacLean, K. E. (2015). Cuddlebits: Friendly, low-cost furballs that respond to touch, in: Proceedings of the international conference on multimodal interaction (ICMI) (Seattle, WA), 365-366. https://doi.org/10.1145/2818346.2823293

Chang, W-L., Šabanovic, S., Huber, L. (2013). Use of seal-like robot PARO in sensory group therapy for older adults with dementia. In Proceedings of the ACM/IEEE international onference on humanrobot interaction (HRI '13), (pp. 101-102). https://doi.org/10.1109/ HRI.2013.6483521

Coeckelbergh, M. (2011). Humans, animals, and robots: A phenomenological approach to human-robot relations. International Journal Social Robotics, 3, 197-204. https://doi.org/10.1007/s12369-10100075-6.

De Carolis, B., Ferilli, S., Palestra, G. (2017). Simulating Empathic Behavior in a Social Assistive Robot. Multimedia Tools and Application, 76, 5073-5094. https://doi.org/10.1007/s11042-0163797-0

Eachus, P. (2001). Pets, people and robots: The role of companion animals and robopets in the promotion of health and wellbeing. International Journal of Health Promotion Education, 39, 7-13. https://doi.org/10.1080/14635240.2001.10806140. 
Fong, T., Nourbakhsh, I., Dautenhahn, K. (2003). A survey of socially interactive robots. Robotics and Autonomous Systems, 42 (3-4), 143-166. https://doi.org/10.1016/S0921-8890(02)00372-X

Forlizzi, J., Gemperle, F., DiSalvo, C.F. (2003). Perceptive sorting: A method for understanding responses to products. In DPPI 2003, Proceedings of the 2003 International Conference on Designing Pleasurable Products and Interfaces June 23-26, 2003 (pp. 103108), Pittsburg, PA, USA. https://doi.org/10.1145/782896.782922

Friedman, B., Kahn, P.H., Hagman, J. (2003). Hardware companions? What online AIBO discussion forums reveal about the human- robotic relationship. In Proceedings of CHI 2003, ACM Press (pp. 278-280). https://doi.org/10.1145/642611.642660

Frennert, S., \& Östlund, B. (2014). Review: Seven matters of concern of social robots and older people. In International Journal of Social Robotics, 6, 299-310. https://doi.org/10.1007/s12369-013-0225-8.

Fujita, M. (2001). AIBO: Towards the era of digital creatures. International Journal of Robotics Research, 20, 781-794. https:// doi.org/10.1177/02783640122068092

Garrity, A. (2019). These Realistics Robotic Pets That Help Seniors With Dementia Have Race Review on Amazon, In GH, Retrieved 12 on February 2021, https://urly.fi/24HU

Heerink, M., Diaz, M., Albo-Canals, J., Angulo, C., Barco, A., Casacuberta, J., Garriga, C., (2012). A field study with primary school children on perception of social presence and interactive behavior with a pet robot, In Proc. ROMAN, 2012. https://doi.org/ 10.1109/ROMAN.2012.6343887

Heerink, M., Kröse, B., Evers, V., Wielinga, B. (2007). Observing conversational expressiveness of elderly users interacting with a robot and screen agent. In IEEE 10th international conference on rehabilitation robotics (ICORR) IEEE, 751-756. https://doi.org/10.1109/ ICORR.2007.4428509

Heerink, M., Kröse, B., Wiwlinga, B., Evers, V. (2006). Human-Robot User Studies in Eldercare: Lessons Learned. In ICOST '06 International Conference Smart Homes Heal. Telemat (pp. 3138). https://doi.org/10.24140/issn.1645-7250.rle46.10

Heljakka, K., \& Ihamäki, P. (2019). Robot dogs, interaction and ludic literacy: Exploring smart toy engagements in transgenerational play. In (Eds.) A. Teodoro, J.V. bras, \& N.N. Goncalves, (2019). Revista Lusofono de Educacao, 46, 153-169.

Huang, L., Picart, J., \& Gillan, D. (2020). Toward a generalized model of human emotional attachment. Theoretical Issues in Ergonomics Science, 22, 178-199. https://doi.org/10.1080/1463922X.2020. 1790690.

Hudson, S., Lim, S., L., Bentley, P. J., Bianchi-Berthouze, N., Bowling, A. (2011). Investigating the suitability of social robots for the wellbeing of the elderly. In Proceedings of the International Conference on Affective Computing and Intelligent Interaction (ACII) (Memphis, TN) (pp. 578-587). https://doi.org/10.1007/9783-642-24600-5 61

Ihamäki, P. \& Heljakka K. (2021). Robot dog intervention with the Golden pup: Activating social and empathy experiences of elderly people as part of intergenerational interaction. In Proceedings of the 54th Hawaii international conference on systems sciences (pp. 1888-1897). https://doi.org/10.24251/HICSS.2021.230

Ihamäki, P. \& Heljakka, K. (2020). Social and Emotional Learning with a Robot Dog: Technology, Empathy and Playful Learning in Kindergarten. In 9th Annual Arts, Humanities, Social Sciences and Education Conference 6-8 of January 2020, Honolulu Hawaii, United State of America

Jeffrey-Wilensky, J. (2019). Why robotic pets may be the next big thing in dementia care, in NBC news 19.3.2019, accessed 9 on July 2020, https://www.nbcnews.com/mach/science/why-robotic- petsdementia-care-may-be-next-big-thing-ncna990166.

Jones, C., \& Deeming, A. (2008). Affective human- robotic interaction. In C. Peter \& R. Beale (Eds.), Affect and emotion in human- computer interaction, volume 4868 of LNCS. Springer. https://doi.org/ 10.1007/978-3-540-85099-1 15

Jones, S. E., \& Yarbrough, A. E. (1985). A naturalistic study of the meaning of touch. In Communication Monography, 52, 19-56. https://doi.org/10.1080/03637758509376094.

Johanson, DL., Ahn, HS, MacDonald BA., Ahn, BK., Lim, J., Hwang, E., Sutherland, CJ., Broadbent, E. (2019). The Effect of Robot Attentional Behaviors on User Perceptions and Behaviors in a Simulated Health Care Interaction: Randomized Controlled Trial. Journal of Medical Internet Research, 21(10). https://doi.org/10. $2196 / 13667$

Joy for All Companion Pets, Golded Pup, Ageless Innovation Joy For All Companion Pets Golden Lifelike \& Realistic. Amazon, Retrieved 12 of February 2021, https://amzn.to/369RC8n

Jung, M. M., Poel, M., Reidsma, D., \& Heylen, D. K. J. (2017). A first step towards the automatic understanding of social touch for naturalistic human-robot interaction. Front. ICT, 4(3). https://doi.org/ 10.3389/fict.2017.00003

Jøranson, N., Pedersen, I., Rokstad, A. M., \& Ihlebaek, C. (2015). Effects on symptoms of agitation and depression in persons with dementia participating in robot-assisted activity: A cluster- randomized controlled trial. Journal of the American Medical Directors Association, 16(10), 867-873. https://doi.org/10.1016/j.jamda.2015.05.002

Kahn, P.H., Friedman, B., Perez-Granados, DR., Freier NG. (2004a). Robotic pets in the lives of preschool children. In Proceedings of CHI 2004 (pp. 1449-1452). ISSN 1572-0373 / E-ISSN 1572-0381. John Benjamins Publishing Company

Kahn, P. H., Friedman, B., Perez-Granados, D. R., \& Freier, N. G. (2004a). Robotic pets in the lives of preschool children. In Proceedings of CHI, 2004, 1449-1452.

Kahn, P.H., Freier, N.G., Friedman, B., Severson, R.L., Feldman E. (2004b). Social and moral relationships with robotic others? In proceedings of the 13th international workshop on robot and human interactive communication, 545-550, Piscataway, NJ: Institute of Electrical and Electronics Engineering (IEEE).

Kanamori, M., Suzuki, M., \& Tanaka, M. (2002). Maintenance and improvement of quality of life among elderly patients using a pet-type robot. In Japanese Journal of Geriatrics, 39, 214-218. https://doi. org/10.3143/geriatrics.39.214

Kachouie, R., Sedighadeli, S., Khosla, R., \& Chu, M.-T. (2014). Socially assistive robots in elderly care: A mixed-method systematic literature review. International Journal of Human Computer Interaction, 30, 369-393. https://doi.org/10.1080/10447318.2013.873278.

Keys, C. L. (2002). The mental health continuum: From languishing to flourishing in life. Journal of Health Social Behaviour, 43, 207-222. https://doi.org/10.102307/3090197.

Knight, H., Toscano, R., Stiehl, W. D., Chang, A., Wang, Y., and Breazeal, C. (2009). Real-time social touch gesture recognition for sensate robots, in: Proceedings of the international conference on intelligent robots and systems (IROS) (St. Louis, MO), (pp. 37153720). http://dx.doi.org/10.1109/IROS.2009.5354169

Lazar, A., Thompson, H., Piper, A. M., Demiris, G. (2016). Rethinking the Design of Robotic Pets for Older Adults. In DIS 2016, June 4-8, 2016, Brisbane, Australia. https://doi.org/10.1145/2901790. 2901811

Lee K.M., Nass, C. (2003). Designing Social Presence of Social Actors in Human Computer Interaction. In Proceedings of the 2003 Conference on human factors in computing systems, CHI 2003, 
April 5-10, 2003 (pp. 289-296), , Ft. Lauderdale, Florida. https:// doi.org/10.1145/642611.642662.

Leite, I., Pereira, A., Martinho, C., Paiva A. (2008). A re-emotional robots more fun to play with? In Robot and Human Interactive Communication, 2008. RO-MAN2008. The 17th IEEE International Symposium (pp. 77-82). https://doi.org/10.1109/ ROMAN.2008.4600646

Liang, A., Piroth, I., Robinson, H., MacDonald, B., Fisher, M., Nater, U. M., Skoluda, N., \& Broadbent, E. (2017). A pilot randomized trial of a companion robot for people with dementia living in the community. Journal of American Medical Directors Association, 18(10), 871-878. https://doi.org/10.1016/j.jamda.2017.05.019

Looije, R., Neerincx, M., \& de Lange, V. (2008). Children's responses and opinion on three bots that motivate, educate and play. Journal of Physical Agents, 2, 13-20. https://doi.org/10.14198/JoPha.2008.2. 2.03

Marsilio, J., McKittrick, S., Garner, M., Umbell, L., Maiewski, S., Wenos J. (2018). Effects of a robotic cat on agitation and quality of life in individuals with dementia in a long-term care facility. In JMU Scholarly Common Physician Assistant Capstone, https:// commons.lib.jmu.edu/pacapstones/35/.

Marti, P., Pollini, A., Rullo, A., \& Shinbata, T. (2005). Engaging with artificial pets. In proceedings of the 2005 annual conference on European association of cognitive ergonomics. ACM international conference proceedings series, 132, 99-106.

Melson, G. F., Kahn, P. H., Beck, A., \& Friedman, B. (2009). Robotic pets in human lives: Implications for the human-animal bond and for human relationships with personified technologies. Journal of Social Issues, 65(3), 545-567. https://doi.org/10.1111/J.15404560.2009.01613.X

Miklósi, A., \& Gácsi, M. (2012). On the utilization of social animals as a model for social robotics. In Frontiers in Psychology, 19(75). https://doi.org/10.3389/fpsyg.2012.00075.

Moyle, W., Beattie, E., Draper, B., Shum, D., Thalib, L., Jones, C., O'Dwyer, S., \& Mervin, C. (2015). Effect of an interactive therapeutic robot animal engagement, mood states, agitation and psychotropic drug use in people with dementia: A cluster- randomized controlled trial protocol: Table 1. BMJ Open, 5(8), 1-6. https://doi. org/10.1136/bmjopen-2015-009097

Moyle, W., Cooke, M., Beattie, E., Jones, C., Klein, B., Cook, G., \& Gray, C. (2013). Exploring the effect of companion robots on emotional expression in older adult with dementia: A pilot randomized control trial. Journal of Gerontological Nursing, 39(5), 4653. https://doi.org/10.3928/00989134-20130313-03

Nácher-Soler, V.E., García Sanjuan, V., Jaén, Fi, Martínez, F.J. (2015). Game Technologies for Kindergarten Instruction: Experiences and Future Challenges.

Neven, L. (2010). But obviously not for me: Robots, laboratories and the defiant identity of elder test users. Sociaology and Health \& Illness, 32(2), 335-347. https://doi.org/10.1111/j.1467-9566.2009.01218.x

Norman, D. A. (2004). Emotional design: Why we love (or hate) everyday things. Basic Books.

Norouzi, H., Kim, K., Lee, M., \& Schubert, R. (2019). Walking your virtual dog: Analysis of awareness and proxemics with simulated support animals in augmented reality, 2019 IEEE international symposium on mixed and augmented reality (ISMAR). Beijing, China, 2019, 157-168. https://doi.org/10.1109/ISMAR.2019.000-8.

Paro, Robot. http://www.parorobots.com/, 2019.

Petersen, S., Houston, S., Qin, H., Tague, C., \& Studley, J. (2017). The utilization of robotic pets in dementia care. Journal of Alzheimer's Disease, 55(2), 569-574. https://doi.org/10.3233/JAD-160703
Powers, A. Kiesler, S. (2006). The advisor robot: Tracing People's mental model form a Robot's physical attributes. In Proceedings on the 1st ACM SIGGHI/SIGART conference on human-robot interaction (pp. 218-225), Salt Lake City, Utah, USA. https://doi.org/10.1145/ 1121241.1121280

Reeves, B., \& Nass, C. (1996). The media equation: How people treat computers, television, and new media like real people and places. Cambridge University Press.

Robinson, H., MacDonald, B., \& Broadbent, E. (2015). Physiological effects of a companion robot on blood pressure of older people in residential care facility: A pilot study. Australasian Journal on Ageing, 34(1), 27-32. https://doi.org/10.1111/ajag.12099

Šabanović, S. (2010). Robots in Society, Society in Robots. International Journal of Social Robotics 2(4), 439-450. https://doi.org/10.1007/ s12369-010-0066-7

Saito, T. Shibata, K. Wada, K., Tanie, K. (2003). Relationship between interaction with the mental commit robot and change of stress reaction of the elderly. Proceedings of IEEE international symposium on computational intelligence in robotics and automation, CIRA 2003, kobo, Japan, 119-24.

Saldien J, Goris K, Vanderborght B, Vanderfaeillie J, Lefeber D. (2010). Expressing emotions with the social robot Probo. International Journal of Social Robot 2, 377-389. https://doi.org/10.1007/ s12369-010-0067-6

Schulman-Marcus, J., Mookherjee, S., Rice, L., \& Lyubarova, R. (2019). New approaches for the treatment of delirium: A case for robotic pets. American Journal of Medicine, 132(7), 781-782. https://doi. org/10.1016/j.amjmed.2018.12.039

Sefidgar, Y. S., MacLean, K. E., \& Yohanan, S. Van der Loos, H.M., Croft, E.A. and Garland, E.J. (2016). Design and evaluation of a touch-Centred calming interaction with a social robot. In IEEE Trans. Affect. Computer, 7, 108-121. https://doi.org/10.1109/ TAFFC.2015.2457893.

Sharkey, A., Sharkey, N. (2012). Granny and the robots: Ethical issues in robot care for the elderly. In Catherine Hasse and Dorte Marie Sondergard (Eds.) Designing robots, designing humans (pp. 132146), Routledge Taylor \& Francis Group, NY, USA. https://doi.org/ 10.1109/MRA.2010.940151

Sharkey, A., \& Sharkey, N. (2011). Children, the elderly, and interactive robots. IEEE Robotics and Automation Magazines, 18(1), 32-38.

Sharkey, A., Wood, N., Aminuddin, R. (2020) Robot companions for children and older people. In designing robots, designing humans, Catherine hasse and Dorte Marie Sondergard (Eds.). Routledge Taylor \& Francis Gorup, NY, USA, 132-146.

Shibata, T, (2011). Research on interaction between human and seal robot, PARO. Journal of the robotics Society of Japan, 29(1), 31-34. https://doi.org/10.7210/jrsj.29.31

Shibata, T., Wada, K. (2008). Robot therapy at elder care institutions: Effects of long-term interaction with seal robots. In A. Helal, M. Mokhtari, B. Abdulrazak (Eds.), Theengineering handbook of smart technology for aging, disability, and independence (pp. 405-418). New York: Wiley

Shibata, T., \& Wada, K. (2011). Robot therapy: A new approach for mental healthcare of the elderly A mini review. In Gerontology, 57, 378-386. https://doi.org/10.101159/000319015

Shibata, T., Tanie, K. (2001) Physical and affective interaction between human and mental commit robot. In Proceedings of the IEEE International Conference on Robotics and Automation, ICRA' 01, 2001. https://doi.org/10.1109/ROBOT.2001.933010

Silvera-Tawil, D., Rye, D., \& Velonaki, M. (2014). Interpretation of social touch on an artificial arm covered with an EIT-based sensitive 
skin. International Journal of Social Robotics, 6, 489-505. https:// doi.org/10.1007/s12369-013-0223-x.

Smith, K. (2020). Lifelike robotic pets are helping isolated seniors avoid loneliness, in CNN, retrieved 12 of February $2021 \mathrm{https} / / /$ edition. cnn.com/2020/08/11/us/seniors-robotic-pets- loneliness- wellnessscn-trnd/index.Html Sony AIBO. Retrieved 12 of February 2021http://www.sony- aibo.com/, 2019.

Sony AIBO. Retrieved 12 of February 2021 http://www.sony-aibo.com/, 2019.

Stiehl, W. D., Lieberman, J., Breazeal, C., Basel, L., Lalla, L., and Wolf, M. (2005). Design of therapeutic robotic companion for relational, affective touch. In Proceedings of International Workshop on Robot and Human Interactive Communication (ROMAN) (Nashville, TN) (pp. 408-415). https://doi.org/10.1109/ROMAN.2005.1513813

Tamura, T., Yonemitsu, S., Itoh, A., Okawa, D., Kawakami, A., Higashi, Y., Fujimoto, T., \& Nakajima, K. (2004). Is an entertainment robot useful in the care of elderly people with severe dementia? Journals of Gerontology Series A: Biological Sciences and Medical Sciences, 59A, (pp. 83-85). https://doi.org/10.1093/gerona/59.1.M83

Turkle, S., Breazeal, C., Daste, O., Scasselati, B. (2006a). First encounters with Kismet and cog: Children respond to relational artifacts. In Messaris, P. \& Humphreys (Eds.) Digital media: Transformations in human communication. New York: Peter Lang Publishing. https://doi.org/10.1080/09540090600868912

Turkle, S, Taggart, W., Kidd, C.D., Daste, O. (2006b) Relational artifacts with children and elders: The complexities of cyber companionship. In Connection Science 18(4), 347-362.

Wada, K., Shibata, T. (2006). Robot therapy in a care house: Its sociopsychological and physiological effects on the residents. In Proceedings of the 2006 International Conference on Robotics and Automation (pp. 3966-3971), Orlando, Florida. https://oi. org/10.1109/ROBOT.2006.1642310

Wada, K., \& Shibata, T. (2007). Living with seal robots - Its sociopsychological and physiological influences on the elderly at a care house. Trans. Robot., 23, 972-980. https://doi.org/10.1109/TRO. 2007.906261

Wada, K., Shibata, T., Saito, T., Sakamoto, K., and Tanie, K. (2005). Psychological and social effects of one year robot assisted activity on elderly people at a health service facility for the aged. In Proceedings of the International Conference on Robotics and Automation (ICRA), (pp. 2785-2790), Barcelona, Spain. https:// doi.org/10.1109/ROBOT.2005.1570535

Wada, K., Shibata, T., Saito, T., \& Tanie, K. (2004). Effects of robotassisted activity for elderly people and nurses at a day service center. Proceedings of the IEEE, 92, 1780-1788. https://doi.org/10.1109/ JPROC.2004.835378.

Weiss, A., Wurhofer, D., Tscheligi, M. (2009). "I love this dog"Children's emotional attachment to the robotic dog AIBO. In International journal of social robot 1, 243-248. Springer Science \& Business Media BV 2009. https://doi.org/10.1007/s12369-0090024-4

Yohanan, S., \& MacLean, K. E. (2012). The role of affective touch in human-robot interaction: Human intent and expectations in touching the haptic creature. International Journal of Social Robotics, 4, 163 180. https://doi.org/10.1007/s12369-011-0126-7.

Yokoyama, A., Ribi, F.N., and Turner, D. C. (2004). A comparison of Japanese and Swiss children's behavior toward a pet robot. Paper presented to the international conference on human-animal interaction, Glasgow, Scotland.

Publisher's Note Springer Nature remains neutral with regard to jurisdictional claims in published maps and institutional affiliations.

Pirita Ihamäki holds Doctor of Philosophy and Master of Science in Economics degrees. She is currently working as a Liaison Manager at Prizztech Ltd. and is leading a project called "Open Platform Entrepreneurship Education" for Future Work that aims to plan and build a digital platform that supports work-life balance and collaboration between educational institutions, universities, companies, and international ecosystems as well as to gamify entrepreneurship education concepts. She belongs to the Robocoast EDIH (European Digital Innovation Hub) consortium, where she leads the Innovation Ecosystem and Networking service and manages international relationships. Ihamäki's aim is to boost Europe's innovation capacity, digital competitiveness, and green growth together with strong European Digital Innovation Hub networks. Her aim is to improve innovation ecosystem and networking services for small and medium companies in Finland and across Europe. She is also a leader in the Gamecoast Network, which has around 55 members representing different levels of education professionals, ecosystems of internationalization, and small and medium companies in the fields of gamification, media, creativity, artificial intelligence, augmented reality, and virtual reality. Ihamäki is a researcher focusing on gamification and service design, including the Internet of Toys and robot toys, and is interested in research innovation in building ecosystems. As innovations in services develop, there is an increasing need for research into not only emerging practices and developments but also the methods that enable, support, and promote such unfolding changes. Finally, as a counterbalance to industrial robotics, my research takes me to use social robots and toy robots in teaching, elderly daycare centres to create activities for example intergenerational play between elderly and kindergarten children.

Katriina Heljakka (Doctor of Arts, MA Art history, M.Sc. Economics), Toy and play researcher, visual artist and designer of playful interventions, leads the Pori Laboratory of Play research group at University of Turku (digital culture studies). Her doctoral dissertation on adult play(fulness) in contemporary toy cultures for Aalto University was examined in 2013. Previously, she has worked in the Academy of Finland funded research projects Ludification and Emergence of Playful Culture and Centre of Excellence in Game Culture Studies, in the Hybrid Social Play project funded by Business Finland, and as a designer, Creative Manager and Play Experience Lead in the toy industry. Heljakka's academic articles have been featured in publications by New York University Press, Routledge, Palgrave, Springer, and in multiple scientific journals. She currently studies technologically-driven play, connected toys, physical playful environments, tools and techniques in the workspace, and the visual, material, digital and social cultures of play. 